\title{
SCENARIOS AND MANAGEMENT OF E-WASTES
}

\section{ADITYA DASH \& MANAS NANDA}

Department of Management, Siksha 'O' Anusandhan (Deemed to be University), Bhubaneswar, Odisha, India

\begin{abstract}
This paper gives a review of information on the overall creation of electrical and electronic waste and the deals of new electrical and electronic gadgets. The complete amount of e-squander delivered in 2014 added up to around 41 million tons, expanding at 3-5\% every year. An examination has likewise been talked about between the created esquander, the fierce residential item and the nation's populace, which demonstrates the GDP of any world to be straightforwardly connected to that nation's e-squander. There is no noteworthy effect on the number of inhabitants in the nation. The paper further features the significance and the upsides of reuse by exhibiting what strategies the reusing plants really use. This situation consolidates the most significant components of e-waste and stretches out to all nations that try to gather information and arrange e-squander measurements. At last, the systems can be worked to give a helpful e-squander review of the nation's market for electronic and electrical items just as its exhibitions in e-squander age and assortment. This model was furnished as per an e-squander classification. Pertinent information may as of now be accessible in the nation's storehouses for improvement of pointers. The aides additionally incorporate open source reports, forms, nation models and insights that help nations to produce their own projections if there is no data. At long last, the situation, sway arrangement and the board and how it influences the earth has been talked about right now.

KEYWORDS: E-Waste, E-Squander the Board, Information and Communication Technology (ICT), Market Diagram, Statics
\end{abstract}

Received: Jun 08, 2020; Accepted: Jun 28, 2020; Published: Aug 26, 2020; Paper Id.: IJMPERDJUN2020896

\section{INTRODUCTION}

Electronic waste (electronic waste) is one of the nation's most quickly developing waste sources. Expanded the utilization of electronic hardware exponentially by the Information and Communication Technologies (ICT) advertise. Progressively quick out of date quality and consequent updates of electronic items urge purchasers to dispose of old items, which thusly gather colossal e-squander from the strong waste stream. The non-formal industry utilizes obsolete and dangerous ways to deal with reuse enormous e-squander. To determine the issue would need to be satisfactory authoritative activities and savvy, eco-accommodating innovative arrangements. Electro relatives (E-scraps) are the most broadly known about relinquished and end-of-life hardware items running from PCs, ICT gadgets, home machines, sound and video items and every one of its peripherals. Be that as it may, the e-squander definition on the planet isn't concurred nor is it by and large acknowledged[1].

Electronic waste involves by and large generally expensive and basically tough items that are utilized in private and business household information preparing, media communications or amusement. E-squander isn't risky on the off chance that it is put away in safe stockpiling or reused utilizing logical techniques or shipped in parts or in entire inside the proper division starting with one spot then onto the next. All things considered, if the esquander is reused through unique procedures, it is viewed as perilous. The waste electronic contains various 
substances, including overwhelming metals, plastics, glass and so on, which, if not took care of in a naturally stable manner, can turn out to be conceivably poisonous and perilous to the earth. In the nonformal area, reusing of e-waste can hurt nature utilizing crude strategies. The specialized issues that unavoidably happen during count ought to likewise be handled through a procedure. For instance, the order of e-squander as metal waste is now and then not e-squander[2].

The part of e-squander can't be estimated and can accordingly be difficult to assess in databases. Be that as it may, there is likewise exchange between nations in e-squander, which the figures ought to likewise reflect. The ICT Technology Measurement Alliance shaped the 2013 E-Waste Measurement Task Group (TGEW) to help gather dependable information on e-waste as a system for political dynamic and further advancement on ecologically inviting upkeep of the ICT foundation utilized and end-of-life. In January 2015, the primary issue of the direction was given. The principal Global E-squander Monitor was propelled in 2015 and has increased a huge media introduction in excess of 70 nations nearby its expository work. The run of the mill scope of creating nations is $10 \%$ to $25 \%$. Some immature nations need framework for squander treatment and laws on squander the executives and authorization. As an outcome, the casual area regularly treats e-squander in those nations in an imperfect way.

This has genuine natural and human wellbeing suggestions. E-waste ought to be dealt with so as to treat it in an earth sound way. This implies making and keeping up a practical program, constructing or updating a reusing system and implementing wellbeing and security principles for labourers, to give some examples criteria. Enormous floods of undocumented e-squander are additionally found in created nations which can be (unlawfully or semi-lawfully) dealt with or discarded utilizing second rate benchmarks. At present, there is a lot of disparity between authentic/legislative information and scholastic information. Every accessible datum could take care of into such a framework, ideally connecting to factual groupings and existing systems. Such a fit structure and estimation would assist with interpreting esquander related information and to arrange e-squander insights that are practically identical between nations around the world[3].

\section{GROUPING}

The issue of the e-squander classification will be replied before really expounding on the figuring procedure. Electronic waste, or e-squander, is alluded to as waste with no reuse by any electrical or electronic gear (EEE) that has been discarded by the proprietor (Step Initiative, 2014). Numerous kinds of EEE items are accessible available, making it critical to order them in reasonable and commonsense classes. There are numerous definitions which can be utilized for portray e-squander, every one of which is possibly helpful in the present evaluation framework as a base for e-squander measurements.

The characterization framework ought to likewise not be excessively totaled, as contrasts between nations will be hard to decipher. For instance, shows for Cathode Ray Tube (CRT) can likewise be designated to IT, however they can be allotted to family unit gadgets in different nations, while screens may be connected to different nations. A further model is that microwave gadgets can be archived either as little family unit gadgets or as enormous residential machines in different nations[4].

Those announcing ambiguities will hence influence data. A characterization framework for e-squander details would recognize things by comparable capacity, similar substance quality and relating end-of-life attributes (regarding risky substances and valuable materials). Likewise, a homogenous normal conveyance of weight and lifetime inside a similar classification ought to be accessible to rearrange the quantitative appraisal of comparable items. Eventually, e- 
squander items with a ton of potential data ought to likewise be named huge or ecologically related things independently. There is just a single arrangement framework that satisfies these criteria: the United Nations standard. This order is alluded to as:

\section{Processed Material Insights}

The market is separated into metal, plastics, glass and different materials based on handled material. Elastic, wood, compressed wood, concrete and earthenware production likewise are incorporated. In 2016, the metal area spoke to the market's driving offer. It is probably going to post a CAGR of over $4.0 \%$ over the gauge time frame. Parts that utilization metal circles, wire fastens and conductive materials incorporate Digital and Electrical gadgets. Metals are for the most part utilized in every segment, printed circuit sheets and microcontrollers, which is assessed to have the most elevated development over the figure time frame right now. In addition, because of expanded plastics use in different electric gadgets, including nourishment processors, PCs, pots, lawnmowers and telephones, the plastic portion is anticipated to proceed with solid development over the forecast time frame. The divisions of glass and different items are relied upon to increment from 2017 to 2025 at a humble development rate[5].

\section{Source Insights}

In the 2016 e-squander the board showcase, the purchaser hardware section contributed extraordinarily. The marvel is on track until 2025. Isolated into family machines, handheld electronic gadgets, IT adornments, IT gear, and PCBs can be shopper hardware. The principle explanation behind filling the interest for purchaser hardware was broad selection of the previously mentioned gadgets in the private and business areas. IT and Telecom hardware and clinical gear are a piece of modern gadgets. The section can be driven by the developing pace of advancement of IT and telecom specialist co-ops in blend with the developing social insurance industry around the world.

\section{Application Insights}

The segment can be changed into squander and reuse based on utilization. The market overwhelmed in 2016 by the removal fragment. Electric waste is discarded in three procedures: squander removal, re-use and copying. In any case, both waste removal and cremation have been seen to have a noteworthy negative effect on the earth and on human wellbeing. Reuse, however, is a financially savvy and effective method for lessening worldwide power creation.

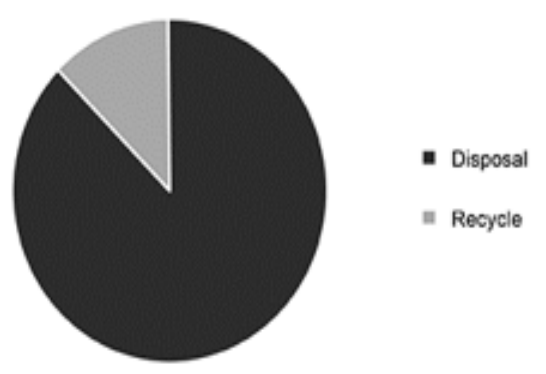

Figure.l: Global E-Waste Management Market Revenue Share

Figure 1: Shows Global E-Waste Management Market Revenue Share Graph of Disposal and Recyclable Garbage. 
Also, reusing may report considerable compound yearly development rate (CAGR) abundance of $3.5 \%$ over a similar range because of worldwide backing efforts directed by different Governments and Nongovernmental association (NGOs) concentrated on effective e-squander removal, preparing and reusing. Organizations like Microsoft, Dell, HP and Panasonic have just acquainted activities with sort out huge recovery programs with the end goal of reusing and reuse old gear through associations with reusing organizations[6].

\section{Regional Insights}

In current situation, Asia Pacific is on the forefronts. At a CAGR, improvement is assessed at 6.0 percent over the projection time frame. Expanded discretionary cash flow and the becoming spousal of electronic gadgets in the creating and created economies establish one of the key market energizers for development in the locale. Created nations like the United States and the United Kingdom additionally Export to Asian nations a lot of the e-squander they produce and it is anticipated to well be foreseen in the territorial market over the expectation time frame. Moreover, the Middle East and Africa district is required to post the most noteworthy CAGR over the conjecture time frame attributable to unlawful dumping of e-squander from created nations combined with rising government guidelines for orderly assortment and reusing of electronic piece in the locale. The market in Europe is ready to encounter moderate development inferable from decrease in e-squander age in these regions[7].

\section{E-WASTE MANAGEMENT MARKET SHARE INSIGHTS}

Electronic Recyclers International, Inc.; Enviro-Hub Holdings Ltd.; MRI (Australia) Pty ltd.; Sims Recycling Ltd.; Umicore S.A.; and Waste Management, Inc. were among the key players holding significant pieces of the overall industry. Advertised organizations put resources into innovative work to dispatch practical reusing hardware that is mechanically best in class. Because of various reusing firms and the disorderly area occupied with advanced piece preparing, rivalry in the market stays extreme. Furthermore, the fundamental impetus for expanding rivalry are government plans and initiatives.

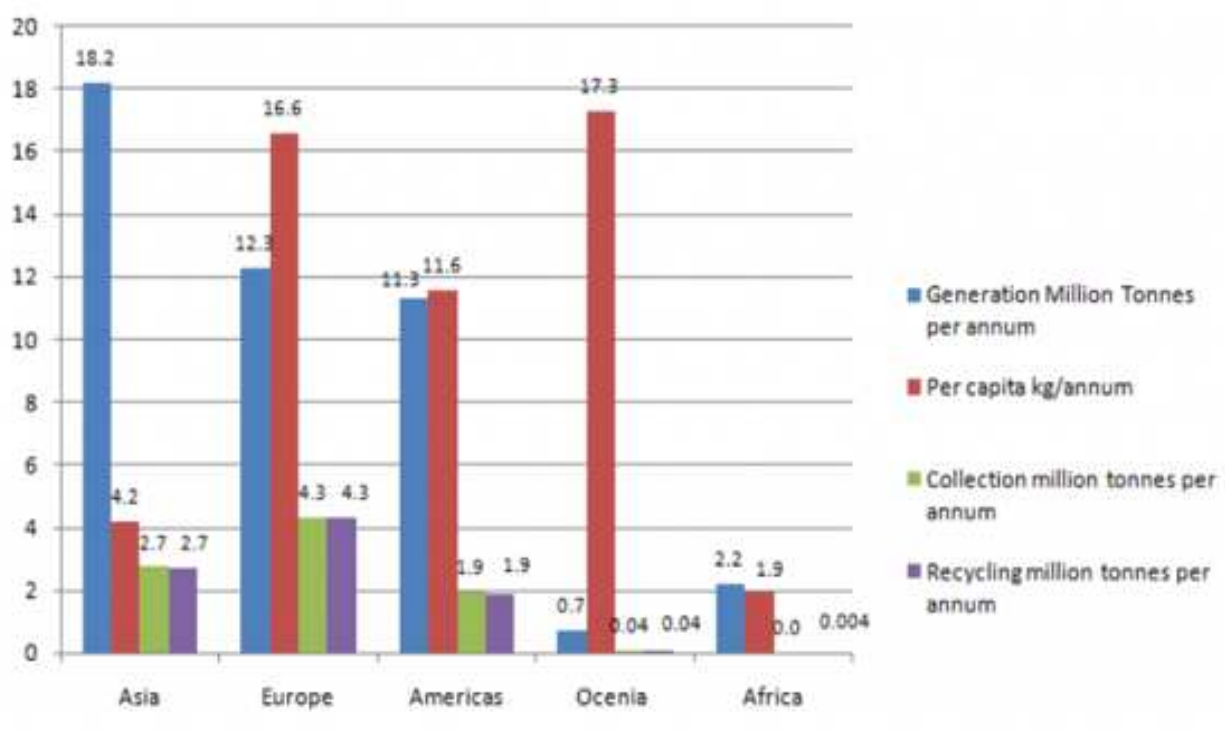

Figure.2: E-Waste Production across the World

Figure 2 


\section{Low Awareness in Developed Regions Would Slow the E-Waste Management Activities}

In the majority of the world as shown in Figure 2, the issues brought about by e-squander are really not comprehended. You don't yet understand the effect this contamination will have on the environment and wherever on the planet there is a predetermined number of reusing programs. The absence of tight administrative structures in numerous nations further intensifies this reality. In any case, the circumstance around the globe is steadily changing, fundamentally as a few associations ' activities and exacting administrative structure are shaping to an ever increasing extent. It definitely prompts expanded e-squander the board rehearses, which in the following scarcely any years will make a helpful environment[8].

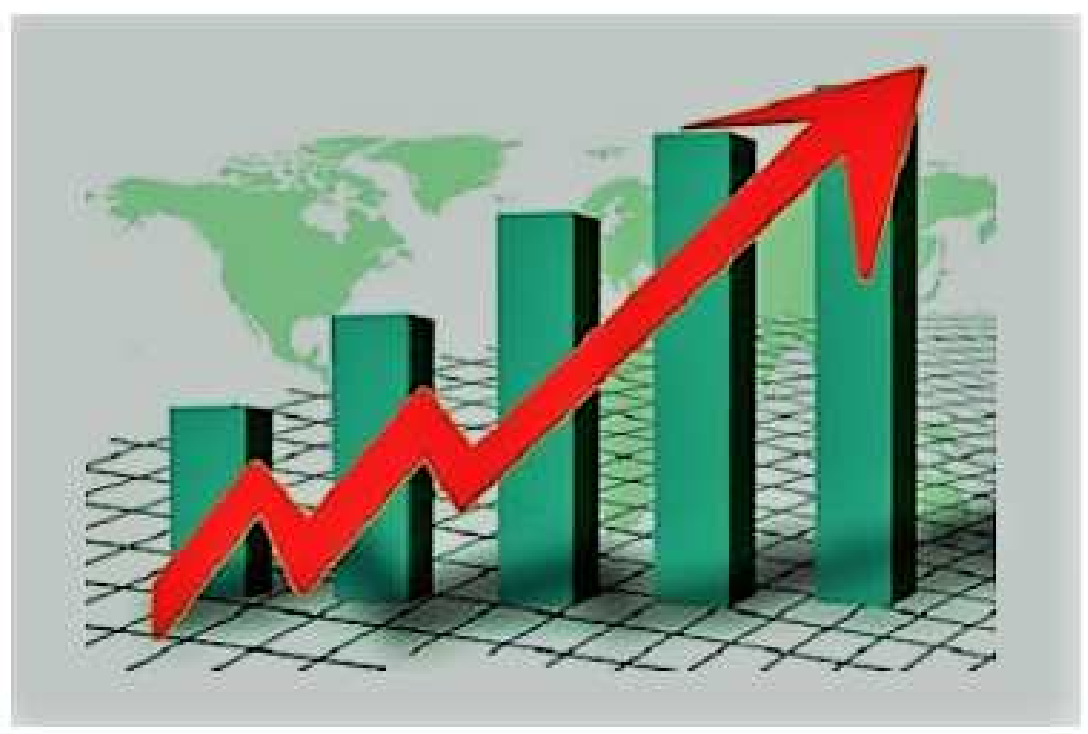

Figure.3: E-waste Management Overview

Figure 3

\section{IMPACTS OF E-WASTE ON THE ENVIRONMENT}

Electronic waste will be squander from all way of hardware, from PCs and cell phones to household gadgets, including nourishment processors, pressures, cookers and so forth. There is little data about the natural impact of ill-advised removal of this E-squander, yet these impacts present genuine dangers and risks to the worldwide atmosphere overall which is increasing day by day as illustrated in Figure 3.

\section{Effects on Air}

One of the most well-known impact of E-squander on air is through air contamination. For instance, a British narrative about Lagos and its occupants, called Welcome to Lagos, shows various landfill foragers who experience various landfills in Lagos searching for inappropriately arranged gadgets which incorporates wires, blenders, and so on, to make some pay from the reusing of these squanders. These men were appeared to consume wires to get the copper (an entirely important ware) in them by outside consuming which can discharge hydrocarbons into the air[9].

\section{Effects on Water}

At the point when gadgets containing substantial metals, for example, lead, barium, mercury, lithium (found in cell phone and PC batteries), and so on., are inappropriately arranged, these overwhelming metals drain through the dirt to reach 
groundwater channels which in the long run rush to the surface as streams or little lakes of water. Neighborhood people group regularly rely upon these waterways and the groundwater. Aside from these synthetic compounds bringing about the demise of a portion of the plants and creatures that exist in the water, admission of the defiled water by people and land creatures brings about lead harming. A portion of these overwhelming metals are additionally cancer-causing.

\section{FINAL THOUGHTS ON THE EFFECTS OF E-WASTE ON THE ENVIRONMENT}

As should be obvious, the impacts of e-squander on the earth can be decimating. Despite the fact that the long haul impacts of e-squander are as yet obscure, it positively has some negative effect on soil, water, and air quality. These are for the most part fundamental pieces of a sound planet. Green E-squander Recycling Center offers a removal drop-off area for occupants and a get administration for organizations. These administrations spread the significant Silicon Valley urban areas, to be specific San Jose, Santa Clara, Sunnyvale, Fremont, Milpitas, Campbell, Cupertino, Mountain View, Palo Alto, and Redwood City. This inside and numerous others have cutting edge innovation and particular specialists that work superbly of appropriately reusing e-squander. These practices will help return the planet to a condition of parity[10].

\section{CONCLUSIONS}

E-waste's perilous nature is one of the world's quickly developing ecological issues. Extending the issue is the everexpanding measure of e-squander related with absence of mindfulness and sufficient capacity. Required data on the sheltered treatment of e-waste and individual security ought to be given to these staff. Some specialized arrangements are accessible for e-squander the board, however requirements, for example, guidelines, assortment framework, foundation, and staff ought to be set up to be actualized in the administration framework. People that live for significant stretches of time and expanded the danger of non-biodegradable waste on the planet. The dangers presented by inadmissible natural removal in the end influence individuals. Perilous, costly and valuable metals can be found in e-squander. The e-squander is commonly comprised of $30 \%$ plastics, $30 \%$ stubborn and $40 \%$ metals. E-squander speaks to a little yet developing part of the about 2.01 billion metric huge amounts of strong waste created worldwide consistently.

\section{REFERENCES}

1. P. Kiddee, R. Naidu, and M. H. Wong, "Electronic waste management approaches: An overview," Waste Manag., 2013, doi: 10.1016/j.wasman.2013.01.006.

2. C. P. Balde, V. Forti, V. Gray, R. Kuehr, and P. Stegmann, The global e-waste monitor 2017. 2017.

3. M. Kaya, "Recovery of metals and nonmetals from electronic waste by physical and chemical recycling processes," Waste Management. 2016, doi: 10.1016/j.wasman.2016.08.004.

4. V. K. Garlapati, "E-waste in India and developed countries: Management, recycling, business and biotechnological initiatives," Renewable and Sustainable Energy Reviews. 2016, doi: 10.1016/j.rser.2015.10.106.

5. F. Suja, R. Abdul Rahman, A. Yusof, and M. S. Masdar, "e-Waste Management Scenarios in Malaysia," J. Waste Manag., 2014, doi: 10.1155/2014/609169.

6. O. Tsydenova and M. Bengtsson, "Chemical hazards associated with treatment of waste electrical and electronic equipment," Waste Management. 2011, doi: 10.1016/j.wasman.2010.08.014.

7. S. Herat and P. Agamuthu, "E-waste: A problem or an opportunity? Review of issues, challenges and solutions in Asian countries," Waste Management and Research. 2012, doi: 10.1177/0734242X12453378. 
8. B. Tansel, "From electronic consumer products to e-wastes: Global outlook, waste quantities, recycling challenges," Environment International. 2017, doi: 10.1016/j.envint.2016.10.002.

9. G. Gaidajis, K. Angelakoglou, and D. Aktsoglou, “E-waste: Environmental problems and current management,” Journal of Engineering Science and Technology Review. 2010, doi: 10.25103/jestr.031.32.

10. C. R. de Oliveira, A. M. Bernardes, and A. E. Gerbase, "Collection and recycling of electronic scrap: A worldwide overview and comparison with the Brazilian situation," Waste Manag., 2012, doi: 10.1016/j.wasman.2012.04.003. 
